\title{
An Application of Bilevel Optimization in Pricing and Leasing Strategy
}

\author{
Suthee Thitiananpakorn and Pisit Jarumaneeroj
}

\begin{abstract}
This paper focuses on the finding of an optimal pricing and leasing strategy for both the third-party warehouse and customers, whose conflicts lie on their contradictory objective functions, via bilevel optimization approach. Bilevel optimization is a game-based approach where the third-party warehouse is a leader, who first decides the price of short and long-term rental contracts taking the behavioral reaction of other players, that is, customers and its competitor, into consideration. Once observed, customers then decide which contracts to be chosen so that their objectives are optimized. While complicated, under certain assumptions, we can show that closed-form solutions could be derived. Our experimental results indicate that competitor storage price significantly affects both third-party warehouse's profit and all of its customer's total costs. Besides, large customer tends to suffer more from high opportunity cost; but, the delivery cost charged by the third-party warehouse is crucial for small customer's rental decision.
\end{abstract}

Index Terms-Bilevel programming, game theory, storage pricing, third-party warehouse.

\section{INTRODUCTION}

Third-party warehouses have played an important business role in the networks of several supply chains as they provide storage buffer against fluctuating demand and supply. Warehousing and storage leasing industry is also one of the fastest growing businesses nowadays. According to the National Bureau of Statistic (NBS) of China, in 2013, the Chinese national warehousing fixed asset was about 69.2 billion dollars, increasing by $32.7 \%$ when compared to 2012's figure [1].

In terms of operations, warehousing companies provide storage services with fixed capacity, measured in pallets, to a wide range of customers; and, storage pricing is crucial for both storage providers and customers as it directly affects their operational costs - and so profitability [2]. In addition, as storage space could be considered a perishable product - it loses value if left unoccupied - and some warehouses are equipped with special equipment, i.e. refrigerated warehouse, utilizing this storage space to its maximum potential is also a typical goal for those warehousing companies [3]. In order to achieve such a goal, effective partnership strategies between warehousing companies and customers are thus required as they could turn opportunity cost into mutual benefit - and be allocated to each player [4].

Manuscript received June 16, 2018; revised December 23, 2018. The authors are with the Department of Industrial Engineering, Faculty of Engineering, Chulalongkorn University, Bangkok, Thailand (e-mail: Suthee.T@student.chula.ac.th, Pisit.ja@chula.ac.th).
Long-term storage space leasing schema is one of such strategies, where a warehouse reserves part of its space for long-term leasing, and the rest for contingency use, i.e. short-term leasing. Based on this schema, the warehouse is beneficial from the reduction of potentially idle space, while the customers could enjoy a cheaper unit price from the warehouse [5]. However, as both short and long-term prices, along with the prices set by its competitors, directly affect the decisions made by customers - and so the warehouse's optimal pricing and leasing strategy is, therefore, needed so that both players could enjoy the surplus gained by a rationale decision making process [6].

In order to better understand the behavior of both warehousing companies and customers in a dynamic setting, in this paper, a bilevel optimization model is developed and applied on a simple system consisting of two warehouses the third-party warehouse and its competitor — and $|I|$ customers. For simplicity, we assume that the third-party warehouse knows its customers' demand patterns over the planning horizon; and it is responsible for the delivery to the customers. Additionally, the third-party warehouse offers two types of leasing contracts, that is, short and long-term ones, while the competitor provides only one fixed leasing contract. While the price offered by competitor and that of the warehouse's long-term contract are rather stable, the price of the short-term contract gradually rises based on the usage length. For clarity, Fig. 1 shows the comparison of unit storage prices from all leasing contracts.

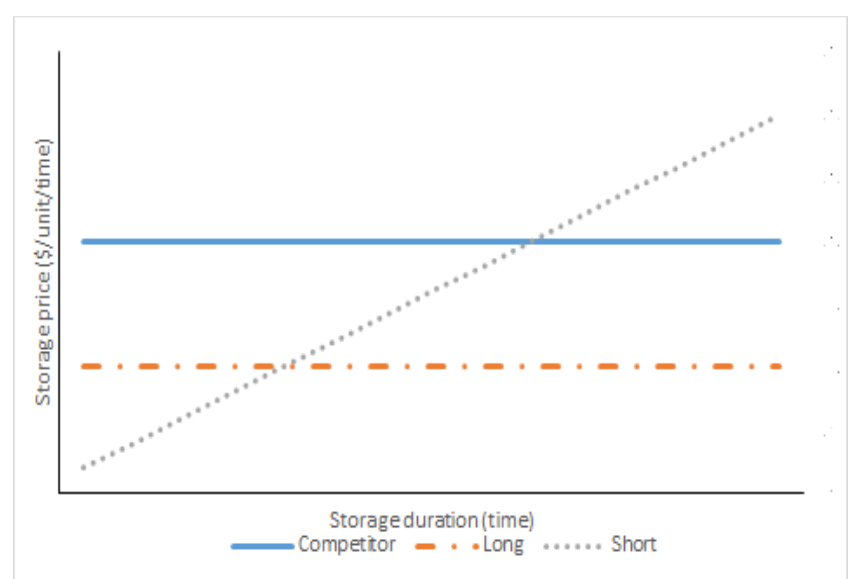

Fig. 1. Warehouse's and competitor's unit storage prices.

Based on this setting, our proposed procedure will first let the warehouse decide on storage pricing, and, once observed, customers will then decide on appropriate inventory planning so that the leasing cost is minimized. As we assume that both players are rationale, the warehouse can then iteratively evaluate the best pricing strategy based on its customer's and 
competitor's responses.

\section{BILEVEL OPTIMIZATION MODEL}

The notations to be used are listed as follows. Indices

- $\quad i$ is an index for customers $(i=1, \ldots, I)$.

- $\quad j$ is an index for planning cycles $(j=1, \ldots, J)$.

- $\quad t$ is an index for time periods, where $t \in[0, T]$; and, $\mathrm{T}$ denotes the ending period of the whole planning horizon.

Constants and parameters

- $\quad C W$ denotes storage capacity of the warehouse (units).

- $\quad C$ denotes storage price charged by the competitor (\$/unit/time).

- $H C$ denotes inventory holding cost at the warehouse (\$/unit/time).

- $O C^{c}$ denotes opportunity cost for exorbitant storage space rented by customers (\$/unit/time).

- $\quad O C^{w}$ denotes opportunity cost for rented-but-unused storage space at the warehouse (\$/unit/time).

- $\quad P C$ denotes penalty cost for excessively rented storage capacity at the warehouse (\$/unit/time).

- $d_{c}$ denotes delivery cost of the competitor (\$/delivery).

- $d_{w}$ denotes delivery cost of the warehouse (\$/delivery).

- $U_{i}$ denotes inventory usage rate of customer $i$ (units/time).

- $\quad N_{i j}$ denotes number of deliveries to customer $i$ in planning cycle $j$ (deliveries).

- $\quad T_{i j}^{b}$ is the starting time of planning cycle $j$ of customer $i$.

- $\quad T_{i j}^{e}$ is the ending time of planning cycle $j$ of customer $i$.

- $\quad T_{i j}$ is the duration of planning cycle $j$ of customer $i$.

- $Q_{i j}$ is the quantity of customer $i$ 's product needed to be stored at the warehouse in planning cycle $j$ (units), where $Q_{i j}=\int_{T_{i t}^{b}}^{T_{i t}^{e}} D_{i}(t) d t$ and $T_{i t}^{e}=T_{i t+1}^{b}$.

Functions

- $D_{i}(t)$ is the demand function of customer $i$.

- $Z W\left(p^{l}, p^{s}\right)$ is the profit function of the warehouse, which is a function of short and long-term prices.

- $Z C_{i}\left(x_{i}^{l}, n_{i j}\right)$ is the total cost function of customer $i$, which is a function of short (number of deliveries) and long-term contracts.

Decision variables

- $p^{s}$ is a nonnegative decision variable representing unit price of short-term leasing space at the warehouse (\$/units/time).

- $p^{l}$ is a nonnegative decision variable representing unit price of long-term leasing space at the warehouse (\$/units/time).
- $x_{i}^{l}$ is a nonnegative integer decision variable representing number of long-term leasing space by customer $i$ at the warehouse (units).

- $n_{i j}$ is a nonnegative integer decision variable representing number of deliveries from the warehouse to customer $i$ in planning cycle $j$ (deliveries) whose calculation is based on short-term leasing space $\left(\frac{n_{i j} Q_{i j}}{N_{i j}}\right)$.

- $X_{t}^{p}$ is excess inventory at the warehouse at time $t$ (units).

- $D_{i j}^{c}$ is number of deliveries from the competitor to customer $i$ in planning cycle $j$ (deliveries).

It is worth noting that our proposed bilevel optimization model is based on Stackelberg Game with two main sets of players, that is, warehouses and its customers [7]. For simplicity, there are only two warehouses and $|I|$ customers, each of which has $|J|$ planning cycles whose lengths are not necessarily equal — but with the same planning horizon. All inventory will be stored at the warehouse at the beginning of each planning cycle and gradually withdrawn during such a cycle. And, the process repeats through the end of planning horizon. As customers may lease both short and long-term space in one particular time period, for economical reason, we assume that inventory will be first drawn from the short-term rental space and then the long-term one [8].

Based on the literature [9], solving a bilevel optimization problem is quite difficult as there is no efficient algorithm to solve large-scale problems to optimality. Therefore, the following assumptions are imposed for tractability.

(1) The unit of storage space for both warehouses are the same.

(2) The capacity of the third-party warehouse is limited.

(3) The competitor warehouse has unlimited capacity.

(4) There must be no beginning and ending inventory at the third-party warehouse.

(5) Shortages at customers are not allowed.

(6) The number of vehicles is sufficiently large.

(7) There is no delivery lead time.

(8) Demand of customer $i$ is generated from the following function, $D_{i}(t)=\mu+\alpha \sin (\pi t / T)$, where $\mu$ is an average demand and $\alpha$ is a standard deviation.

(9) Long-term price is a function of short-term price, $p^{l}=k p^{s}$ where $k$ is a constant $k \geq 1$.

Fig. 2 shows the movement of customer $i$ 's inventory at the third-party warehouse, where the inventory of customer $i$ is fully replenished at the beginning of planning cycle $j\left(T_{i j}^{b}\right)$ and delivered by $Q_{i j} / N_{i j}$ units every $Q_{i j} / U_{i} N_{i j}$ time periods. As the inventory of $Q_{i j} / N_{i j}$ units will be stored at the warehouse for $c \cdot Q_{i j} / U_{i} N_{i j}$ time periods, where $c=\left(1,2,3, \ldots, n_{i j}\right)$, total inventory stored at the warehouse by customer $i$ in planning cycle $j$ could be calculated by (1).

$$
\text { Total Inventory }=\left(\frac{Q_{i j}}{N_{i j}}\right)\left(\frac{Q_{i j}}{U_{i} N_{i j}}\right)\left(\sum_{c=1}^{n_{i j}} c\right)
$$




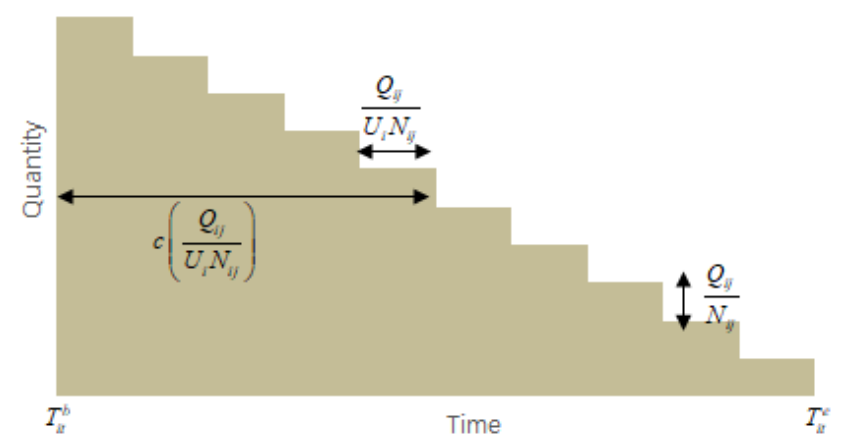

Fig. 2. Inventory movement of customer $i$ at the warehouse.

\section{A. An Optimization Model for the Third-Party Warehouse}

The objective of the third-party warehouse is to determine the optimal storage pricing strategy that maximizes its total profit, subject to two practical constraints that limit the prices of both short and long-term rental contracts, as follows.

$$
\begin{gathered}
\text { Maximize } Z W\left(p^{l}, p^{s}\right)=\sum_{i} \sum_{j} S_{i j}+\sum_{i} \sum_{j} L_{i j}+\sum_{i} \sum_{j} D_{i j} \\
+\sum_{i} \sum_{j} O C_{i j}^{w}-\sum_{i} \sum_{j} H_{i j}-\sum_{j} P_{i j} \\
\begin{array}{c}
S_{i j}=\frac{p^{s} Q_{i j}^{2}}{2 U_{i} N_{i j}^{2}}\left(n_{i j}^{3}+2 n_{i j}^{2}+n_{i j}\right)-\frac{p^{s} Q_{i j}^{3}}{6 U_{i}^{2} N_{i j}^{3}}\left(2 n_{i j}^{3}+3 n_{i j}^{2}+n_{i j}\right) \\
L_{i j}=p^{l} x_{i}^{l} T_{i j} \\
O C_{i j}^{w}=O C^{w}\left[\frac{x_{i}^{l} Q_{i j}}{2 U_{i} N_{i j}}\left(\frac{x_{i}^{l} N_{i j}}{Q_{i j}}-1\right)+x_{i j}^{l}\left(n_{i j}-\frac{Q_{i j}^{l}}{Q_{i j}}\right) d_{w}\right.
\end{array} \\
H_{i j}=H C\left[x_{i}^{l}\left(\frac{Q_{i j}}{U_{i}}-\frac{x_{i}^{l}}{U_{i}}\right)+\frac{Q_{i j}}{2 U_{i} N_{i j}}\left(\frac{x_{i}^{l} N_{i j}}{Q_{i j}}+1+\frac{Q_{i j}}{N_{i j}}\left(n_{i j}^{2}+n_{i j}\right)\right)\right]
\end{gathered}
$$

$$
P_{i j}=P C \sum_{t} X_{t}^{p}
$$

Subject to:

$$
\begin{gathered}
0 \leq p^{s} \leq C \\
0 \leq p^{l} \leq C
\end{gathered}
$$

The warehouse's objective (2), is simply a finding of prices for both short and long-term contracts $\left(p^{s}\right.$ and $\left.p^{l}\right)$ that maximize its total profit, where (3) - (6) denote the revenues from short-term storage, long-term storage, delivery, and customer's opportunity cost; lastly, (7) and (8) denotes inventory holding and penalty costs at the warehouse, respectively.

- Short-term leasing cost (3) is calculated by the summation of total inventory multiplied by the short-term rental cost, which is an increasing function of storage time $\left(p^{s} t\right.$ where $\left.0<t<T\right)$.
- Customer's opportunity cost (6) is calculated from vacant space rented by the customers from all possible scenarios, i.e. when there is no demand.

- Inventory holding cost (7) is calculated from both short and long-term rental contracts based on total inventory (1).

Lastly, inequalities (9) and (10) help limit the ranges of $p^{s}$ and $p^{l}$ that should not exceed the price set by its competitor.

\section{B. An Optimization Model for the Customers}

As the objective of customers is to minimize their total costs, once the prices of all rental contracts are observed, each customer then decides on the amount of short and long-term leasing space.

$$
\begin{gathered}
\text { Minimize } Z C_{i}\left(x_{i}^{l}, n_{i j}\right)=\sum_{j} S_{i j}+\sum_{j} L_{i j}+\sum_{j} D_{i j} \\
+\sum_{j} O C_{i j}^{c}+\sum_{j} C_{i j}+\sum_{j} D_{i j}^{c} \\
O C_{i j}^{c}=O C^{c}\left[\frac{x_{i}^{l} Q_{i j}}{2 U_{i} N_{i j}}\left(\frac{x_{i}^{l} N_{i j}}{Q_{i j}}-1\right)+x_{i}^{l}\left(T_{i j}-\frac{Q_{i j}}{U_{i}}\right)\right] \\
C_{i j}=\frac{C Q_{i j}^{2} D_{i j}^{c}\left(D_{i j}^{c}+1\right)}{2 U_{i} N_{i j}^{2}} \\
D_{i j}^{c}=\left(N_{i j}-n_{i j}-x_{i}^{l} \frac{N_{i j}}{Q_{i j}}\right) d_{c}
\end{gathered}
$$

Subject to:

$$
\begin{gathered}
1 \leq n_{i j} \leq N_{i j} \\
0 \leq x_{i}^{l} \leq Q_{i j} \\
\frac{x_{i}^{l} N_{i j}}{Q_{i j}}+n \leq N_{i j}
\end{gathered}
$$

The objective of customer $i$ (11) is simply total cost minimization, where the cost function consists of short-term storage cost, long-term storage cost, and delivery cost at the warehouse - Equations (3) - (5), respectively. Equation (12) shows the opportunity cost from leasing idle space, which is similar to (6) but with different parameters. Similar to (3), Equation (13) denotes the cost of leasing space from competitor but with constant price. Equation (14) denotes delivery cost from competitor and Inequalities (15) - (17) limit the ranges of $x_{i}^{l}$ and $n_{i j}$.

\section{SOLUTION PROCEDURE}

Below is the pseudo code of our proposed methodology for solving storage pricing and leasing problems based on bilevel optimization.

\footnotetext{
Pseudo code for the Proposed Bilevel Optimization model

1: Input parameters of warehouses and customers

2: Find values of $x_{i}^{l}, n_{i j}$ by minimizing the following function

$$
F\left(x_{i}^{l}, n_{i j}\right)=S_{i j}+L_{i j}+D_{i j}+O C_{i j}^{c}+C_{i j}+D_{i j}^{c}
$$

3: Differentiate $F\left(x_{i}^{l}, n_{i j}\right)$ with respect to both $x_{i}^{l}$ and $n_{i j}$
} 
4: Find a closed form solution of $x_{i}^{l}, n_{i j}$ and $p^{s}$

5: Let $z=0$

6: $\quad$ while $z \leq N_{i j}$ for each $i$ and $j$ let $n_{i j}=z$

7: $\quad$ Find $p^{s}$ for each value of $n_{i j}$

8: $\quad z+1$

9: $\quad$ end

10: Find all possible $x_{i}^{l}$ for each value of $Q_{i j}, N_{i j}$ and for all values of $p^{s}$ 11: $\quad$ if $x_{i}^{l}$ is not an integer, $x_{i}^{l}=\left\lceil x_{i}^{l}\right\rceil$

12: Find value $n_{i j}$ for each $x_{i}^{l}$

13: $\quad$ if $n_{i j}$ is not an integer

$$
n_{i j}=\arg \min _{\left\{\left[n_{i j}\right],\left\lfloor n_{i j}\right\rfloor\right\}}\left\{F\left(\left[n_{i j}\right\rceil\right), F\left(\left\lfloor n_{i j}\right\rfloor\right)\right\}
$$

14: $\quad$ else $n_{i j}=n_{i j}$

15: if number of deliveries $\frac{x_{i}^{l} N_{i j}}{Q_{i j}}$ is not an integer,

$$
\frac{x_{i}^{l} N_{i j}}{Q_{i j}}=\left\lceil\frac{x_{i}^{l} N_{i j}}{Q_{i j}}\right\rceil
$$

16: Eliminate infeasible solutions

17: Find $x_{i}^{l}, n_{i j}$ that minimize total cost of customer for each value of $p^{s}$

18: Find value of $Z W\left(p^{s}, p^{l}\right)$

19: Find value of $Z W\left(p^{s}, p^{l}\right)$

20: Return optimal values of $p^{s}, x_{i}^{l}, n_{i j}$

From Line 2, given a leasing strategy of one particular customer in one planning cycle, its total cost could be defined by Equation (18).

$$
F\left(x_{i}^{l}, n_{i j}\right)=S_{i j}+L_{i j}+D_{i j}+O C_{i j}^{c}+C_{i j}+D_{i j}^{c}
$$

By differentiating $F\left(x_{i}^{l}, n_{i j}\right)$ with respect to $x_{i}^{l}$ and $n_{i j}$, we can then obtain $F^{\prime}\left(x_{i}^{l}\right)$ and $F^{\prime}\left(n_{i j}\right)$ as shown in Equations (19) and (20).

$$
\begin{aligned}
& F^{\prime}\left(x_{i}^{l}\right)=\frac{C+O C^{c}}{U_{i}} x_{i}^{l}+\left(\frac{p^{l} Q_{i j}}{2 U_{i}}\right)\left(N_{i j}+1\right)-B C\left(N_{i j}-n_{i j}-\frac{1}{2}-\frac{O C^{c}}{2 C}\right) \\
& +\left(d_{w}-d_{c}\right) \frac{N_{i j}}{Q_{i j}}+k p^{s} T_{i j} \\
& F^{\prime}\left(n_{i j}\right)=\frac{Q_{i j}^{3}}{U_{i}^{2} N_{i j}^{3}}\left(\frac{p^{s}}{2}\right) n_{i j}^{2}+\left(\frac{C Q_{i j}^{2}}{U_{i} N_{i j}^{2}}-\frac{p^{s} Q_{i j}^{3}}{2 U_{i}^{2} N_{i j}^{3}}\right) n_{i j}+\frac{Q_{i j}^{3}}{U_{i}^{2} N_{i j}^{3}}\left(\frac{p^{s}}{12}\right) \\
& +\frac{C Q_{i j}^{2}}{2 U_{i} N_{i j}^{2}}\left(\frac{2 N_{i j} x_{i}^{l}}{Q_{i j}}-2 N_{i j}+1\right)+d_{w}-d_{c} \\
& n_{i j}=\left(\frac{1}{2}-\frac{C}{p^{s} B}\right)+\sqrt{\left(\frac{C}{p^{s} B}\right)^{2}+\frac{1}{12}-\left(\frac{C}{p^{s} B}\right)\left(\frac{2 N_{i j} x_{i}^{l}}{Q_{i j}}-2 N_{i j}+2\right)+\left(d_{c}-d_{w}\right) \frac{2}{p^{s} A B}}, \\
& p^{s}=\frac{(4 B-6) C n_{i j}+2 C(6-4 B)\left[2 N_{i j}+1-\left(\frac{2}{B(C+O C)}\right)\left[O C\left(\frac{B}{2}+\frac{Q_{i j}}{U_{i}}-T_{i j}\right)-\frac{B C}{2}\left(2 n_{i j}-2 N_{i j}-1\right)\right]\right]+\frac{6-4 B}{A(C+O C)}\left(d_{c}-d_{w}\right)(5 C+O C)}{\left(9+4 B^{2}-12 B\right) n_{i j}^{2}+\left(12+4 B^{2}-14 B\right) n_{i j}-3 B+\frac{4}{6} B^{2}+3-4 C(6-4 B)\left(\frac{k T_{i j}}{B(C+O C)}\right)} \\
& x_{i}^{l}=\left(\frac{U_{i}}{C+O C^{c}}\right)\left[\begin{array}{l}
O C\left(\frac{B}{2}+\frac{Q_{i j}}{U_{i}}-T_{i j}\right) \\
-\frac{C A N_{i j}}{2 Q_{i j}}\left(2 n_{i j}-2 N_{i j}-1\right) \\
+\left(d_{c}-d_{w}\right) \frac{N_{i j}}{Q_{i j}}-k p^{s} T_{i j}
\end{array}\right],
\end{aligned}
$$

To check whether the critical points from $F^{\prime}\left(x_{i}^{l}\right)=0$ and $F^{\prime}\left(n_{i j}\right)=0$ are indeed global minimizers, we need to check the definiteness of Hessian matrix of $F\left(x_{i}^{l}, n_{i j}\right)$ whose second derivatives with respect to $x_{i}^{l}$ and $n_{i j}$ are shown as follows.

$$
\begin{gathered}
F^{\prime \prime}\left(n_{i j}\right)=\frac{p^{s} Q_{i j}^{3}}{U_{i}^{2} N_{i j}^{3}}\left(n_{i j}-\frac{1}{2}\right)+\frac{C Q_{i j}^{2}}{U_{i} N_{i j}^{2}} \\
F^{\prime \prime}\left(x_{i}^{l}\right)=\frac{C+O C^{c}}{U_{i}} \\
F^{\prime \prime}\left(x_{i}^{l}, n_{i j}\right)=\frac{C Q_{i j}}{U_{i} N_{i j}} \\
F^{\prime \prime}\left(n_{i j}, x_{i}^{l}\right)=\frac{C Q_{i j}}{U_{i} N_{i j}}
\end{gathered}
$$

Based on the determinants of all leading principal minors, (25) and (26), it could be seen that $F\left(x_{i}^{l}, n_{i j}\right)$ is strictly convex. Therefore, the critical points from $F^{\prime}\left(x_{i}^{l}\right)=0$ and $F^{\prime}\left(n_{i j}\right)=0$, i.e. (27) and (28), are indeed the optimal solution to $F\left(x_{i}^{l}, n_{i j}\right)$

where $A=\frac{Q_{i j}^{2}}{U_{i} N_{i j}^{2}}$ and $B=\frac{Q_{i j}}{U_{i} N_{i j}}$. By substituting (27) into (28), we can derive the short-term rental price $\left(p^{s}\right)$ as shown in (29).

$$
\left|F^{\prime \prime}\left(n_{i j}\right)\right|=\frac{p^{s} Q_{i j}^{3}}{U_{i}^{2} N_{i j}^{3}}\left(n_{i j}-\frac{1}{2}\right)+\frac{C Q_{i j}^{2}}{U_{i} N_{i j}^{2}}>0
$$

$$
\left|\begin{array}{l}
F^{\prime \prime}\left(n_{i j}\right) \quad F^{\prime \prime}\left(x_{i}^{l}, n_{i j}\right) \\
F^{\prime \prime}\left(n_{i j}, x_{i}^{l}\right) F^{\prime \prime}\left(x_{i}^{l}\right)
\end{array}\right|=\frac{p^{s} Q_{i j}^{3}}{U_{i}^{2} N_{i j}^{3}}\left(n_{i j}-\frac{1}{2}\right)>0
$$


Since $p^{l}=k p^{s}$, warehouse pricing function (29) defines both short and long-term rental contracts for the warehouse; while (27) and (28) are closed-form solutions for customer reaction.

\section{NUMERICAL EXAMPLE}

For simplicity, we test our proposed model on a simple system consisting of two warehouses - the third-party and its competitor - and two different customers, one being a big customer $(\mathrm{C} 1)$ having more average demand and variation, and another is a comparably small one (C2) with less demand and variation. The model is executed over 360 days, with 3 seasons and 12 planning cycles. The input parameters are drawn from previous research [8].

- $T=360$ days

- $T_{i j}=30$ days

- $H C=\$ 0.1 /$ unit/day

- $C=\$ 1 /$ unit/day

- $O C^{w}=\$ 0.5 /$ unit/day

- $O C^{c}=\$ 0.5 /$ unit/day

- $C W=20,000$ units

- $\quad P C=\$ 1.2 /$ unit/day

- $d_{w}=\$ 50 /$ delivery

- $d_{c}=\$ 155 /$ delivery

- $U_{1}=250$ units/day

- $U_{2}=100 u n i t s /$ day

- $D_{1 j}=218+55 \sin (\pi t / 120)$

- $D_{2 j}=98+7 \sin (\pi t / 120)$

- $\quad N_{1 j}=(165,215,240,200)$

- $\quad N_{2 j}=(80,85,90,95)$

- $N_{i j}$ is for a season and is repeated over the planning horizon.

- The initial inventory is set to zero

Based on this setting, the optimal pricing and leasing decisions of the warehouse and all customers, along with the sensitivity analysis on some key parameters, are shown in Table I.

TABLE I. DeCisions MADE By THE WAREHOUSE AND ALl Customers

\begin{tabular}{|l|cccccc|}
\hline Parameters & $p^{s}$ & $Z W$ & $Z C 1$ & \multicolumn{1}{c}{$Z C 2$} & $x_{1}^{l}$ & $x_{2}^{l}$ \\
\hline Basic & 0.00856 & $1,715,003$ & $1,578,806$ & 302,397 & 518 & 206 \\
$d_{w}=15$ & 0.00837 & $1,432,014$ & $1,356,222$ & 240,749 & 707 & 282 \\
$d_{w}=85$ & 0.00876 & $2,010,271$ & $1,810,627$ & 367,070 & 329 & 131 \\
$d_{w}=120$ & 0.00895 & $2,257,044$ & $1,998,432$ & 430,016 & 139 & 60 \\
$d_{w}=155$ & 0.00931 & $2,432,850$ & $2,130,514$ & 481,731 & 11 & 0 \\
\hline$C=0.3$ & 0.00785 & 441,623 & 497,138 & 242,708 & 2207 & 387 \\
$C=0.65$ & 0.00550 & $1,019,612$ & 984,589 & 203,897 & 690 & 272 \\
$C=1.35$ & 0.01168 & $2,461,491$ & $2,219,043$ & 407,235 & 410 & 165 \\
$C=1.7$ & 0.01482 & $3,227,636$ & $2,878,044$ & 514,116 & 337 & 137 \\
\hline$O C^{c}=0.1$ & 0.00823 & $1,540,539$ & $1,415,462$ & 270,382 & 724 & 296 \\
$O C^{c}=0.3$ & 0.00842 & $1,662,885$ & $1,529,819$ & 289,020 & 605 & 244 \\
$O C^{c}=0.7$ & 0.00867 & $1,751,707$ & $1,614,474$ & 312,905 & 451 & 177 \\
$O C^{c}=0.9$ & 0.00876 & $1,740,224$ & $1,604,351$ & 322,340 & 399 & 156 \\
\hline
\end{tabular}

\section{A. Warehouse's Delivery Charge $\left(d_{w}\right)$}

Expectedly, from Table I, the warehouse's profit $(Z W)$ significantly rises as warehouse's deliver charge $\left(d_{w}\right)$ increases. Since the increase of $d_{w}$ also affects the decisions made by the customers, accordingly, the customers will lease less amount of long-term space and rely more on its competitor. In order to compensate revenue loss, the third-party warehouse needs to react by increasing the price for short-term contract $\left(p^{s}\right)$ resulting in higher values of customers' cost.

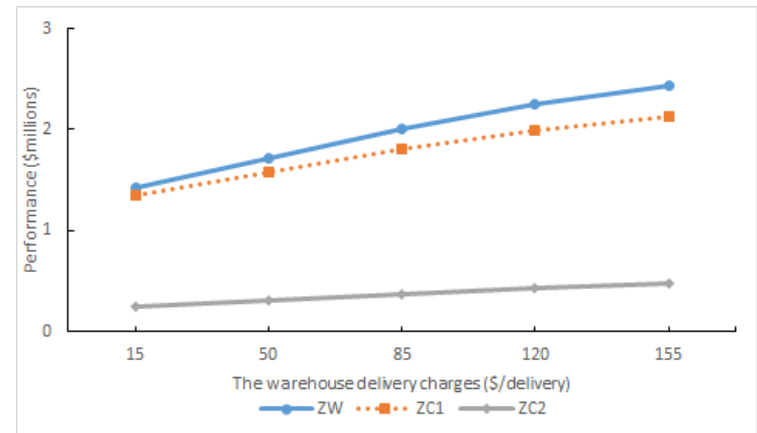

Fig. 3. The impact of change on the warehouse's delivery fare.

If we vary the value of $d_{w}$ from 50 to 85 , the warehouse needs to increase the value of $p^{s}$ from 0.00856 to 0.00876 ; but this would increase the total costs of customer 1 ( $Z C 1)$ and 2 (ZC2) by $14.69 \%$ and $21.39 \%$.

Competitor Storage Price ( $C$ )

From Table I and Fig. 4, the third-party warehouse significantly gains more when the competitor's storage price ( $C$ ) increases - as it has a good chance to charge customers more by increasing the value of $p^{s}$. For example, if we increase the value of $C$ from 1 to $1.7, Z W$ increases by $88.2 \%$ due to the abrupt rise on short-term leasing $\left(p^{s}\right)$ from 0.00856 to 0.01482 - resulting in higher values of $Z C 1$ and $\mathrm{ZC} 2$. However, when $C$ is decreasing to a certain point, i.e. $C=0.3$, the warehouse will not lower the value of $p^{s}$ to compete with the competitor; but, it rather sets $p^{s}$ at a certain high price to attract more long-term leasing customers.

This solution does make a good sense when the opportunity cost of customers is low, as both $\mathrm{C} 1$ and $\mathrm{C} 2$ will react to the warehouse decision by leasing a lot of long-term space due to such a high price of $p^{s}$.

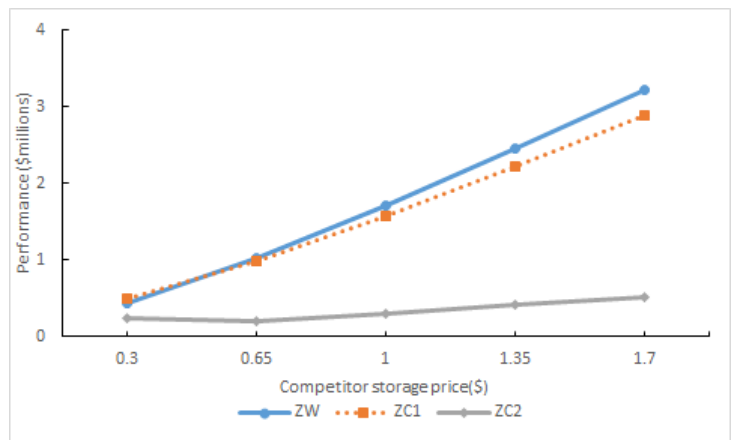

Fig. 4. The impact of change on competitor's storage price. 


\section{B. Customer's Opportunity Cost ( $\left.O C^{c}\right)$}

As we increase customer's opportunity cost $\left(O C^{c}\right)$, the warehouse's profit is observed to rise and then decline as shown in Fig. 5. Intuitively, by increasing customer's opportunity cost, customers should have leased less long-term space and relied more on short-term contracts resulting in higher operational cost.

However, we observe that $\mathrm{ZC1}$ decreases when we increase $O C^{c}$, which seems particularly strange in practice. But, this could be explained by the reaction of the third-party warehouse as it would increase the value of $p^{s}$ to compensate revenue loss. However, if such a cost is too high, the customers will lean toward a cheaper alternative offered by the competitor resulting in a lower cost at customer and a lower profit at the third-party warehouse.

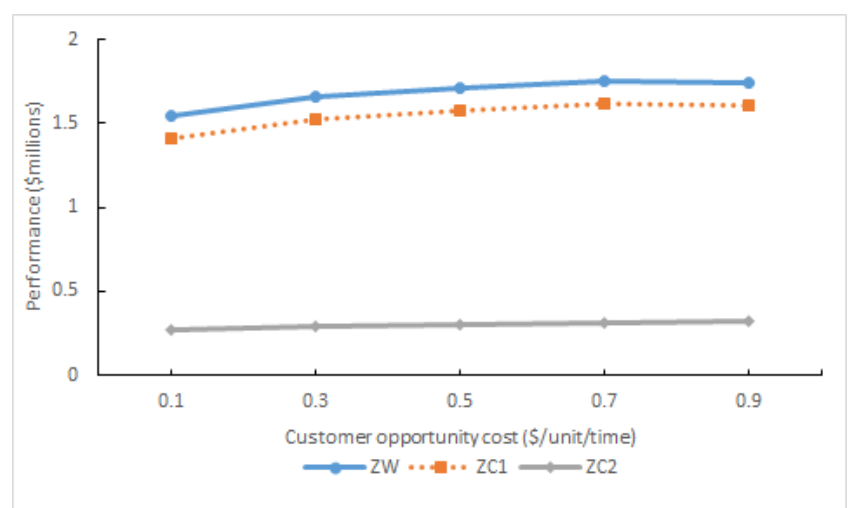

Fig. 5. The impact of change on customer's opportunity cost.

\section{CONCLUSION}

In this paper, we develop a game-based bilevel optimization model for the determination of optimal pricing and leasing strategy for both the third-part warehouse and its customers. A numerical study is also conducted on a small-scale problem with two customers, along with the sensitivity analysis on some important parameters. Our numerical results indicate that the competitor's storage price has remarkable impact on both the warehouse's profit and customers' total cost. Moreover, the warehouse's delivery charge has more impact on small customer - as it could attract more long-term space demands by reducing delivery cost; but, this is not the case for a large customer, with more demand and high variation, as it tends to focus more on opportunity cost.

While we can improve pricing and leasing strategy by the proposed schema, some limitations are worth to be mentioned. Firstly, we assume that long-term price is a function of short-term price, where $p^{l}=k p^{s}$. This however does not hold true in general as the long-term prices depend on several factors, such as seasonality and the amount of space to be leased. Accordingly, it would be interesting to see the changes as this assumption has been relaxed and replaced by some more realistic functions. Secondly, we assume that all customers are the same in terms of bargaining power as we apply the same leasing price to all customers. But, in practice, large customers should be differently treated; and, this would affect both decisions made by the warehouse and other players. Finally, dynamic pricing strategy on different customers with different characteristics should be further studied.

\section{REFERENCES}

[1] X. X. Hao, D. W. Hong, and P. Hongxia, "A robust optimization of capacity allocation policies in the third-party warehouse," Mathematical Problems in Engineering, 2015, pp. 1-10.

[2] K. H. Kim and K. Y. Kim, "Optimal price schedules for storage of inbound containers," Transportation Research Part B: Methodological, vol. 41, no. 8, 2007, pp. 892-905.

[3] Y. Feng and B. Xiao, "Integration of pricing and capacity allocation for perishable products," European Journal of Operational Research, vol. 168, no. 1, 2006, pp. 17-34.

[4] X. Qiu, G. Q. Huang, and J. S. L. Lam, "A bilevel analytical model for dynamic storage pricing in a supply hub in industrial park (SHIP)," IEEE Transactions on Automation Science and Engineering, vol. 12, no. 3, 2015, pp. 1017-1032.

[5] M. A. Cohen and N. Agrawal, "An analytical comparison of long and short term contracts," IIE Transactions, vol. 31, no. 8, 1999, pp. 783-796.

[6] M. Labbé and A. Violin, "Bilevel programming and price setting problems," A Quarterly Journal of Operations Research, vol. 11, no. 1, 2012, pp. 1-30.

[7] B. Colson, P. Marcotte, and G. Savard, "An overview of bilevel optimization," Annals of Operations Research, vol. 153, no. 1, 2007, pp. 235-256.

[8] X. Qiu and G. Q. Huang, "Storage pricing, replenishment, and delivery schedules in a supply hub in industrial park: A bilevel programming approach," International Journal of Production Research, vol. 51, pp. 23-24, 2013, pp. 6950-6971.

[9] V. V. Kalashnikov, S. Dempe, G. A. Pérez-Valdés, N. I. Kalashnykova, and J. F. Camacho-Vallejo, "Bilevel programming and applications," Mathematical Problems in Engineering, 2015, pp. 1-16.

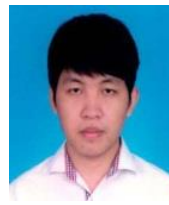

Suthee Thitiananpakorn was born in Bangkok, Thailand, on November 1, 1992. He received the B.Eng. degree in industrial engineering from Chulalongkorn University in 2014. He is currently a master's student at the Department of Industrial Engineering, Chulalongkorn University, Thailand. His main interests are in the areas of operations research and supply chain management.

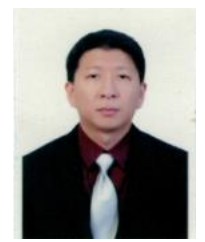

Pisit Jaruamaneeroj is currently an assistant professor at the Department of Industrial Engineering, Chulalongkorn University. He received his Ph.D. in industrial and systems engineering (logistics engineering) from Georgia Institute of Technology. 